The general impression is that this is a useful and reliable supplementary volume and that it amply achieves the purpose for which it is intended.

K. W. LxoN

\section{A SCIENTIST LOOKS AT ART}

\section{Darwin and the Naked Lady}

Discursive Essays on Biology and Art. By Alex Comfort. Pp. vit 170. (London: Routledge and Kegan Paul, Ltd., 1961.) 18s. net.

7 HIS is an entertaining, provocative and illuminating set of essays. It is, at the $\operatorname{sam} \theta \operatorname{time}$, serious minded. It invites us to remember and allow to enter into the consideration of our playing and working, art and the enjoying of art, our knowledge of what we are. We know, but have not yet implemented our knowledge, that we are the products of evolution, tormented by our attempts to keep our true motives and emotions hidden from ourselves. We pay lip service to Darwin and Freud, but go on theorizing as though they had not given us their key concepts of natural selection and the unconscious. Once more, philosophers of art are exhorted to consider the facts and to look at art as one among many human activities, fulfilling or failing to fulfil human needs. More important perhaps, intelligent lookerson at the human scene are exhorted to look more closely at what people, as a matter of fact, enjoy in their reading, looking and listening, and to think less about the standards of the art and literature enjoyed by the cultured few.

The implication is that if this is what satisfies, this should supply the standards of excellence in art. At least, this is what one is led to expect, but Dr. Comfort shies away from his own conclusion. It is as if one of Plato's philosophers, re-entering the cave, were to fall under the old spell all over again, and join in the prajse of those who were adept at noticing resemblances among the shadows. But we cannot have it both ways; either we think that art, like any other human activity, is to be understood in terms of its causes and its functions, or we think that both its causes and its functions are irrelevant to its true nature, that we are, in effect, to look for reasons and not causes in justifying our evaluations. We must also be prepared to accept the implications of the formor view, that if art has a function, it is expendable. Dr. Comfort accepts this implication, and even seems prepared to suggest a substitute for art.

Dr. Comfort presents us with a distinction among thinkers, the soft- and the hard-centred, comparable with William James's tough and tender minded. The crucial difference is said to lie in the willingness of the soft and the tender to accept emotionally satisfying conclusions without waiting on the facts. Dr. Comfort, however, seems to fall into the common scientists' mistake of thinking that what makes a belief scientific is the kind of fact held to be important rather than the attitude towards facts. One can hold unscientific attitudes towards germs and electrons and be scientific about beauty and immortality. A corollary of this mistake is to have a vague general belief that some kinds of statements do not need the support of facts. There is a valuable treatment of Indian erotic art, which, with other chapters, should lead to the conclusion that since they have this adequate substitute release, people of the Indian culture would have less neod than do Europeans of actual orotic experience, and that they would be less anxiety ridden. Is this so ? There is no hint that some facts are needed here-fact and hypothesis are left in the air.

Dr. Comfort makes the further scientists' mistake of extending the sphere of scientific authority from fact and theory to opinion and belief. The final essay, in its occasional insights, and its enormous self-satisfaction, is a model of scientific over-simplification and arrogance. Has Dr. Comfort, after all. forgotten his Freud? Do we not all still have to enter the world by the same route? Do we not all have to find our place in a family where the jealousies and resentments of the established members are only to be matched by the arrogance of the newcomer, who behaves as if the whole family were his slaves? Scientists, like everybody else, show the contrast between wise talk about the family, and intolerant and irrational behaviour in its midst. Scientists are able to keep the illusion that they would be wise rulers only because they so rarely descend into the political arena.

R. L. SAW

\section{STATISTICAL TABLES}

\section{Handbook of Statistical Tables}

By D. B. Owen (Addison-Wesley Series in Statistics.) Pp. xii +580 . (London and Paris: Pergamon Press: Reading, Mass; Palo Alto: Addison-Wesley Publishing Company Inc., 1962) $70 s$.

THIS handbook contains one of the most extensive sets of statistical tables so far published. Its twenty sections include tables relating to all the common distributions, including the multivariate normal and the hypergeometric. Almost one-third of the contents is devoted to non-parametric statistics. with 36 pages given to Wilcoxon tests and 20 to Kolmogorov-Smirnov statistics. Most of the tables have been specially computed; the methods of computation are briefly described, some indications of the use of each table are given and references are made to a bibliography with 251 ontries. Some information is conveyed in the form of graphs or charts, a practice which could usefully have been extended.

Almost all the tables have been reproduced photographically from the output sheets of digital computers, with the aim of eliminating transcription errors. Legibility is good and adequate headings have been inserted by hand. The most serious drawback is the small format; the page size is only 9 in. $\times 6$ in. and the type-area is usually considerably smaller, so that most tables extend ovor several pages.

The author states that, in the choice of tables, he has stressed inaccessible material at the expense of that readily available and himself points out that very little space is given to (for example) the Poisson distribution. The normal distribution provides another example-the usual quantities $P$ and $Z$, together with $Q|Z, P| Z$ and the first three derivations of $Z$ are tabulated for $X=0(0.01) 3.99$, but the inverse tables giving $X$ and $Z$ as functions of $P$ arc so sketchy as to be of little but illustrative value. There are no tables of working values and weights for maximum likelihood probit calculations, or for the other common transformations of proportions, even though the table of $\sin ^{-1} \sqrt{ } \bar{p}$ is to $5 S$ and occupies ten pages. In all, this will be a useful volume on the library shelf, but not one likely to supplant existing collections of tables for day-to-day uso. 